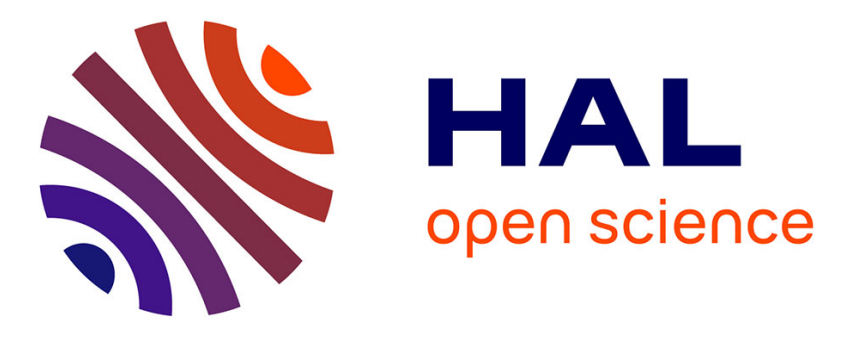

\title{
Design of MICADO advanced passive and active neutron measurement system for radioactive waste drums
}

\author{
Quentin Ducasse, Cyrille Eleon, Bertrand Perot, Abdallah Lyoussi, Oliver \\ Gueton, Massimo Morichi, Erica Fanchini, Andrea Pepperosa, Roger
}

Abou-Khalil, Zakkarya Mekhalfa, et al.

\section{To cite this version:}

Quentin Ducasse, Cyrille Eleon, Bertrand Perot, Abdallah Lyoussi, Oliver Gueton, et al.. Design of MICADO advanced passive and active neutron measurement system for radioactive waste drums. Nuclear Instruments and Methods in Physics Research Section A: Accelerators, Spectrometers, Detectors and Associated Equipment, 2021, 1005, pp.165398. 10.1016/j.nima.2021.165398 . cea-03276008

\section{HAL Id: cea-03276008 https://hal-cea.archives-ouvertes.fr/cea-03276008}

Submitted on 1 Jul 2021

HAL is a multi-disciplinary open access archive for the deposit and dissemination of scientific research documents, whether they are published or not. The documents may come from teaching and research institutions in France or abroad, or from public or private research centers.
L'archive ouverte pluridisciplinaire HAL, est destinée au dépôt et à la diffusion de documents scientifiques de niveau recherche, publiés ou non, émanant des établissements d'enseignement et de recherche français ou étrangers, des laboratoires publics ou privés. 


\section{Design of MICADO advanced passive and active neutron measurement system for radioactive waste drums}

Quentin Ducasse ${ }^{1}$, Cyrille Eleon ${ }^{1}$, Bertrand Perot $^{1}$, Abdallah Lyoussi $^{1}$, Oliver Gueton ${ }^{1}$, Massimo Morichi $^{3}$, EricaFanchini ${ }^{3}$, Andrea Pepperosa $^{3}$, Roger Abou-Khalil ${ }^{5}$, Zakkarya Mekhalfa $^{4}$, Lionel Tondut $^{6}$, Nadia Cherubini² ${ }^{2}$, Giada Gandolfo ${ }^{2}$, Luigi Lepore ${ }^{2}$

${ }^{1}$ CEA, DES, IRESNE, Nuclear Measurement Laboratory, F-13108 Saint-Paul-lez-Durance, France

${ }^{2}$ ENEA, Lungotevere grande ammiraglio thaon di revel 76, Roma 000196, Italy

${ }^{3}$ CAEN S.p.A., Via Vetraia 11, Viarregio 55049, Italy

${ }^{4}$ Orano Cycle, Site de Marcoule, Bagnols-sur-Cèze 30200, France

${ }^{5}$ Orano Group, 125 Avenue de Paris, Châtillon 92320 France

${ }^{6}$ Orano La Hague, La Hague 50444, France

\section{Abstract-}

In the frame of the MICADO $\mathrm{H} 2020$ project, a passive and active neutron measurement system is being developed to estimate the nuclear material mass inside legacy waste drums of low and intermediate radioactivity levels. Monte-Carlo simulations have been performed to design a new modular and transportable neutron system, with the main objective to reach a good tradeoff between the performances in passive mode, i.e. neutron coincidence counting, and in active interrogation mode with the Differential Die-away Technique. Different designs are compared, which mainly differ in their moderation materials, graphite and polyethylene. This parametric study allowed us to define a prototype taking into account practical constraints in view of its final implementation in a wide range of in-situ locations and nuclear facilities. The total neutron detection efficiency of the prototype is $6.75 \%$, as calculated for an emptydrum, i.e. without waste matrix. The detection limit in terms of nuclear material equivalent mass have also been estimated based on assumptions for a homogeneous distribution of nuclear materials inside the drum, filled with four types of matrices covering the range of nuclear waste drums defined in the frame of the project. The most favorable matrix is made of stainless steel in passive mode and of polyethylene in active

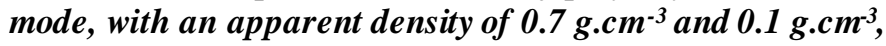
respectively. The calculated mass detection limits are respectively $68 \mathrm{mg}$ of ${ }^{240} \mathrm{Pu}, 62 \mathrm{mg}$ of ${ }^{235} \mathrm{U}$ and $39 \mathrm{mg}$ of ${ }^{239} \mathrm{Pu}$. The most penalizing matrix is made of polyethylene with an apparent density of $0.7 \mathrm{g.cm}^{-3}$, which leads to a mass detection limit of $519 \mathrm{mg}$ of ${ }^{240} \mathrm{Pu}$ in passive mode, and $564 \mathrm{mg}$ of ${ }^{235} \mathrm{U}$ or $349 \mathrm{mg}$ of ${ }^{239} \mathrm{Pu}$ in active mode. Measurement time is 30 min for both passive and active modes. Next steps will be a complete investigation of matrix effects based on intensive Monte-Carlo calculations and an experimental design to figure out the appropriate corrections. Experiments will also be conducted at CEA Cadarache Nuclear Measurement Laboratory with the construction and the assembly of the neutron system prototype, and the measurement of mock-up drums filled with different matrices.

\section{INTRODUCTION}

The MICADO [MIC] (Measurement and Instrumentation for Cleaning And Decommissioning Operations) project of H2020
Research and Innovation Program aims to propose a costeffective and comprehensive solution for non-destructing characterization of nuclear waste by the implementation of different technologies such as gamma cameras, gamma-ray spectroscopy, passive and active neutron measurements, and photofission interrogation technique. The neutron system aims at quantifying nuclear material (mainly Pu and $\mathrm{U}$ isotopes) in technological packages. The objective is to design and build a transportable and modular system inspired by our previous works on security applications [REM17], [CHE16] and [CHE18].

The modularity of the system is defined by its ability to combine both passive neutron coincidence counting [PAN91][CAL86] and active neutron interrogation [CAL86] to allow a wide range of nuclear waste to be characterized. The transportability implies an easy-to-move, compact and relatively light system, while complying with radiation safety rules. The studied designs are based on a transportable neutron generator, polyethylene and graphite materials for neutron reflection, moderation and biological shielding, and modular neutron detection blocks with ${ }^{3} \mathrm{He}$ detectors, including the possibility to add lead shields depending on waste gamma emission rate. In this work, MCNP simulations [MCNP6] have been performed to compare different possible designs of the neutron system.

\section{OUTLOOK OF THE NEUTRON SYSTEM}

The design of a neutron measurement system strongly depends on the characteristics of the nuclear waste drums to be measured. Presently, the need is focused toward technological legacy waste drums up to $400 \mathrm{~L}$ with presence of neutron emitters and fissile isotopes. The wide variety of waste materials will be represented in the numerical model by mixed organic/metallic matrixes with different relative proportions and densities. Larger packages generally show a large quantity of hydrogenous materials, for instance a concrete container, or a cement embedding, or both, which are extremely penalizing in terms of neutron attenuation. Therefore, the photofission interrogation technique will be preferred to characterize nuclear materials in large concrete packages, through the detection of delayed gamma rays [SIM16]. An example of a neutron system design is presented in Figure 1. 


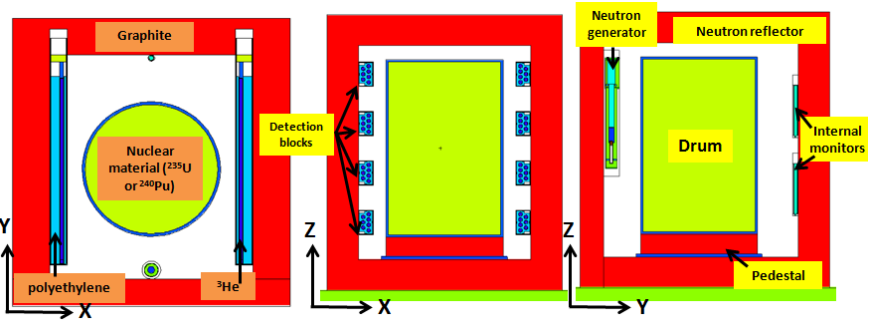

Fig. 1. MCNP model of a neutron system design including a 400 L nuclear waste drum.

The $20 \mathrm{~cm}$ thick external walls of the cell $(150 \mathrm{~cm} \times 160 \mathrm{~cm} \times$ $180 \mathrm{~cm}$ ) are made of graphite, which is a good reflecting material to confine fission prompt neutrons inside the cavity and increase the probability to detect them in the fast neutron detection blocks. The wall behind of the generator is $15 \mathrm{~cm}$ thick. Each block comprises seven ${ }^{3} \mathrm{He}$ detectors of $1 \mathrm{~m}$ length and 4 bar filling pressure, surrounded by polyethylene to slow down fast neutrons and thus improve their capture cross section in ${ }^{3} \mathrm{He}$. Due to the large thermal neutron cross section of the ${ }^{3} \mathrm{He}(\mathrm{n}, \mathrm{p}){ }^{3} \mathrm{H}$ reaction (5330 barns) and low sensitivity to gamma rays, ${ }^{3} \mathrm{He}$ detectors are the golden standard for this application. A thin layer of cadmium $(2 \mathrm{~mm})$ around the detection blocks absorbs residual thermal neutrons due to neutron scattering in the environment, reducing the probability of counting random events in passive neutron coincidence counting. In active neutron mode, this cadmium layer is essential to absorb the thermalized neutrons of the neutron generator. Eight detection blocks are disposed horizontally on the two sidewalls of the system, to give an indication of the vertical location of neutron sources in the drum, in view to reduce uncertainties on the nuclear material mass determination. A free space of a few centimeters between the detection blocks and the drum is saved to put lead plates as a gamma shield in case of highly irradiating wastes. A graphite pedestal and a rotating platform are used to center the drum according to its size (typically from $50 \mathrm{~L}$ to 400 L) in the measurement cavity. Two coated boron detectors (called internal monitors) are placed at the opposite side from the neutron generator. They are sensitive to the thermal neutrons coming from waste materials and will be used to correct the measured signal for matrix effects [AN15]. Finally, an additional boron detector is located outside of the cavity of the cell to monitor the stability of the neutron generator emission.

\section{DEFINITION OF PERFORMANCE METRICS}

MCNP calculations have been performed to investigate the performances in view to design a neutron system in passive and active modes. In passive mode, neutron coincidence counting allows differentiating the neutrons produced in the waste by $(\alpha, n)$ reactions and those from spontaneous fission. In the first case, only one neutron is emitted per reaction, whereas more than one neutron are generally emitted in the fission process. The neutron coincident signal is proportional to the nuclear material mass in the sample, mainly ${ }^{240} \mathrm{Pu}$. Since neutron pairs are detected the performances of the neutron system mainly depend on the square of the total neutron detection efficiency $\varepsilon$, and on the mean neutron lifetime $\mathrm{T}_{1 / 2 \mathrm{~b}}$ in the detection blocks. The lower the latter, the higher the ratio of the real over accidental coincidences [CIF86]. The neutron detection efficiency $\varepsilon$ is calculated via MCNP simulations by calculating ${ }^{3} \mathrm{He}(\mathrm{n}, \mathrm{p}) \mathrm{t}$ reaction rate in the detection blocks. The simulated neutron source has a ${ }^{240} \mathrm{Pu}$ spontaneous fission energy spectrum and it is homogeneously distributed in the $400 \mathrm{~L}$ drum. The $(\mathrm{n}, \mathrm{p})$ reaction rate induced by ${ }^{240} \mathrm{Pu}$ spontaneous fission neutrons is calculated by taking the fission occurrence as origin of time. A mono-exponential fit of the main decay component over time of the $(\mathrm{n}, \mathrm{p})$ reaction rate in the detection blocks leads to the mean neutron lifetime $\mathrm{T}_{1 / 2 \mathrm{~b}}$, as shown in Figure 2.

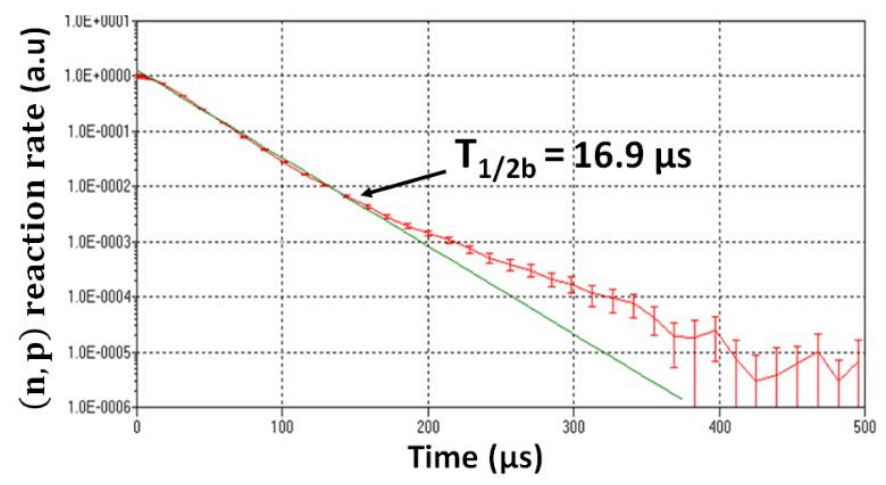

Fig 2: (n,p) reaction rate of the detection blocks for the system shown in Fig. 1. The slope of the mono-exponential fit of the decay (green line) gives $\mathrm{T}_{1 / 2 \mathrm{~b}}$

Given the definition of the neutron detection efficiency and of the mean neutron lifetime in the detection blocks, the best performing neutron system design in passive mode will be characterized by the highest $\varepsilon^{2} / \mathrm{T}_{1 / 2 \mathrm{~b}}$ ratio.

In active mode, a pulsed-mode neutron generator is used as an external neutron source to induce fissions in nuclear materials inside the nuclear waste package (mainly ${ }^{235} \mathrm{U}$ and ${ }^{239} \mathrm{Pu}$ fissile isotopes). The main challenge is to discriminate the useful signal due to induced-fission prompt neutrons from undesirable neutrons embedded in the interrogating flux that is several orders of magnitude higher. A time-energy discrimination technique addresses this issue [PE18], which necessitates minimizing the neutron decay time in the detection blocks $\mathrm{T}_{1 / 2 \mathrm{~b}}$ while maximizing the neutron decay time in the cavity $\mathrm{T}_{1 / 2}$, giving the name of the method known as "differential dieaway" technique. $T_{1 / 2 b}$ and $T_{1 / 2 c}$ are the slope of a monoexponential fit of the fast and slow decay component over time of the $(n, p)$ reaction rate in the detection blocks, respectively, as illustrated in Figure 3. The large signal observed up to $800 \mu \mathrm{s}$ is caused by the detection of the interrogating neutrons emitted during the generator pulse. Then, the useful signal due to ${ }^{235} \mathrm{U}$ induced-fission prompt neutrons emerges from the active background mainly due to photo-neutrons produced by radiative capture gamma rays in cadmium. The large fluctuations in the useful signal and background reflect here only the Monte-Carlo calculation statistics. 


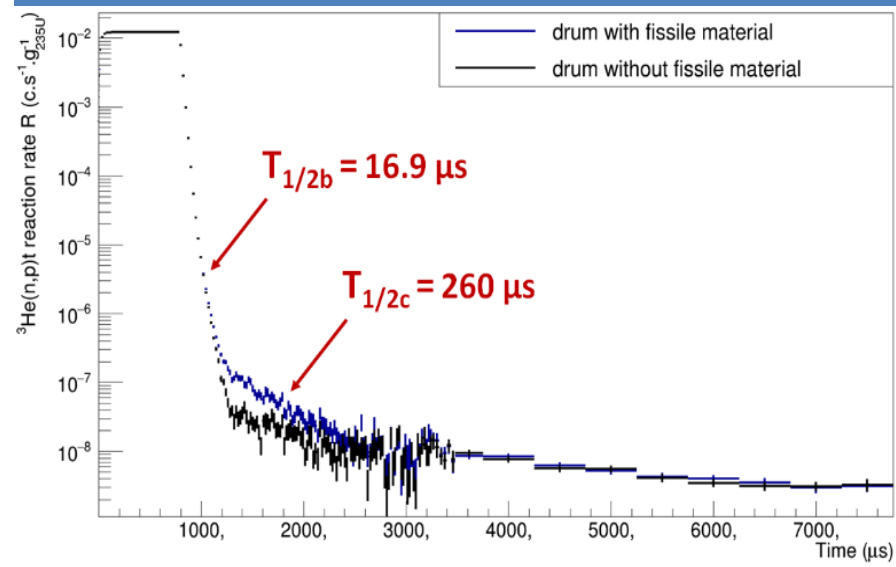

Fig. 3. Calculated ${ }^{3} \mathrm{He}(\mathrm{n}, \mathrm{p})^{3} \mathrm{H}$ reaction rates in active neutron interrogation mode for $1 \mathrm{~g}$ of ${ }^{235} \mathrm{U}$ and without nuclear material (active background).

$\mathrm{T}_{1 / 2 \mathrm{c}}$ is strongly impacted by the thickness and type of materials composing the walls of the measurement cell, while $T_{1 / 2 b}$ mainly depends on the geometry of detection blocks. The performance of a neutron system in active mode is proportional to the neutron detection efficiency $\varepsilon$ of the system, and to the inducedfission rate $\mathrm{R}_{\mathrm{fis}}$ of the interrogated nuclear material. The $\mathrm{R}_{\mathrm{fis}}$ quantity for a homogeneously distributed nuclear material inside the drum is virtually simulated via MCNP by convoluting the calculated average neutron flux inside the drum with the ${ }^{235} \mathrm{U}$ (or the ${ }^{239} \mathrm{Pu}$ ) fission cross section [MCNP6]. By applying the time-energy discrimination technique, the number of induced-fission prompt neutrons detected is estimated by integrating the induced-fission signal in a time gate starting a few hundred $\mu$ s after the end of the pulse (see Figure 3), i.e. when most source neutrons emitted by the generator have disappeared (by absorption or leakage) or have been thermalized. In this way, induced-fission prompt neutrons can be recorded. The comparison between different neutron system designs in active mode relies on the $\varepsilon \times \mathrm{R}_{\mathrm{fis}}$ product, which is proportional to the useful signal. The optimal neutron system will be selected as the best trade-off between the performances in passive and active modes.

\section{COMPARATIVE STUDY OF PRELIMINARY DESIGNS}

The performances are calculated for a case study where $1 \mathrm{~g}$ of nuclear material $\left({ }^{240} \mathrm{Pu}\right.$ in passive mode and ${ }^{235} \mathrm{U}$ in active mode) is homogeneously distributed inside the drum. Six preliminary designs of the neutron system are presented in Figure 4, which essentially differ in their neutron reflector material (graphite and/or polyethylene walls) and in the optional presence of two additional moderation blocks around the generator.
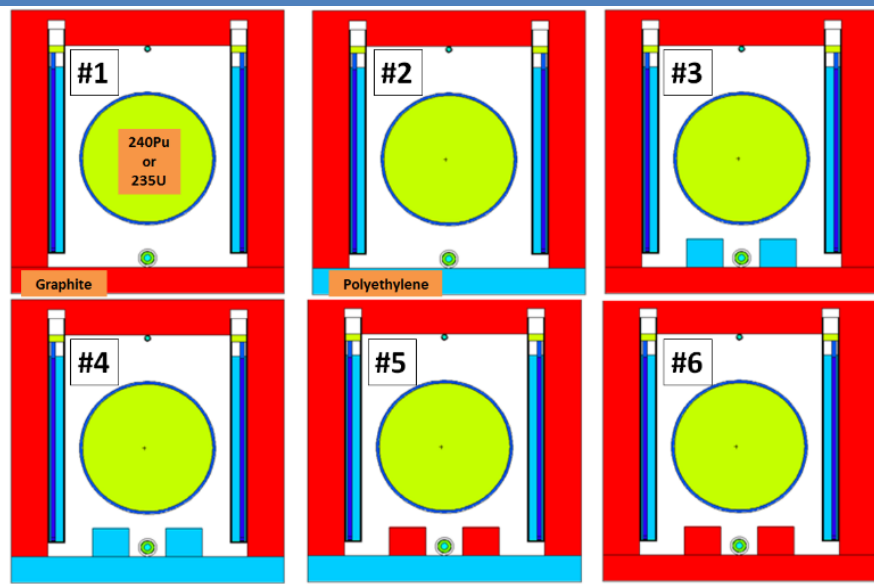

Fig. 4. MCNP upper views of the different neutron system designs.

Polyethylene is a practical alternative to graphite to limit the total weight of the system due to its lower density $\left(0.95 \mathrm{~g} . \mathrm{cm}^{-3}\right.$ versus $1.746 \mathrm{g.cm}^{-3}$ ) and its excellent neutron moderation properties, allowing the use of thinner walls. A higher moderation of the interrogative neutron flux induces a higher induced-fission rate (noted $\mathrm{R}_{\text {fis }}$ further), making polyethylene especially attractive in active mode. On the other hand, polyethylene is not used as a reflector behind detection blocks, as it significantly reduces neutron detection efficiency (noted $\varepsilon$ ). Indeed, the energy of backscattered neutrons is lower with hydrogen nuclei in polyethylene than with carbon nuclei in graphite, leading to a larger absorption by the cadmium layers surrounding the detection blocks. Detection efficiency is a key parameter in passive coincidence counting, in which the useful signal of neutron pairs is proportional to $\varepsilon^{2}$. The two blocks present around the generator in designs \#3 to \#6 are intended to further thermalize and focus interrogating neutrons toward the drum, which increases the fission rate and reduces neutron leakage out of the cell. In active mode, induced-fission prompt neutrons are detected between the pulses of a $14 \mathrm{MeV}$ DT neutron generator (GENIE16 from SODERN, [GEN16]), with an average emission of $2.10^{8}$ neutrons per second. It delivers $200 \mu$ s pulses at a frequency of $125 \mathrm{~Hz}$, i.e. every $8000 \mu$ s. The evolution of the fission prompt neutron signal (represented by the product $\varepsilon \times \mathrm{R}_{\mathrm{fis}}$ ) after the pulse is shown in Figure 5 for the six neutron system designs. 


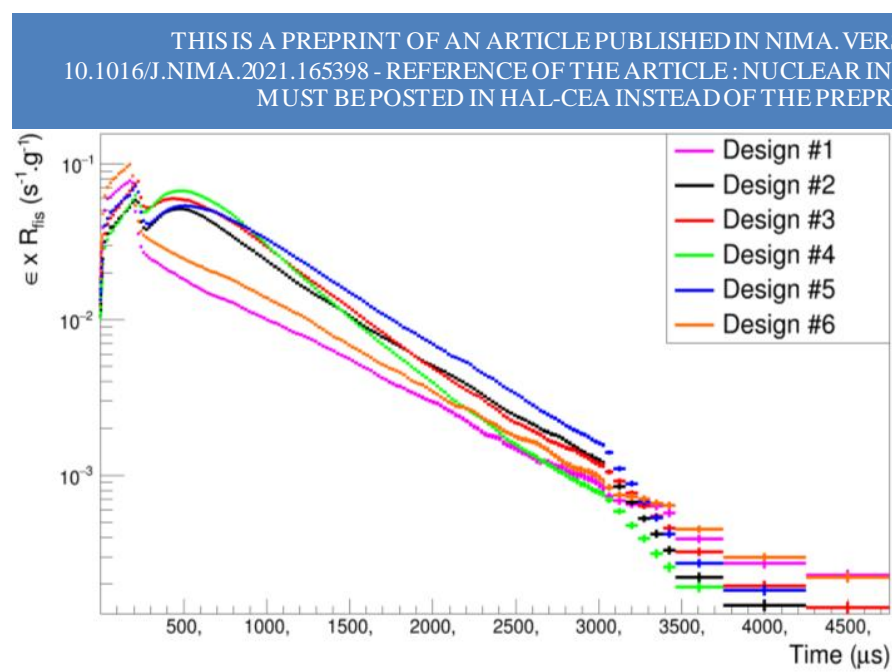

Fig. 5. Evolution of $\varepsilon \times \mathrm{R}_{\mathrm{fis}}$ after the $200 \mu$ s generator pulse, for $1 \mathrm{~g}$ of ${ }^{235} \mathrm{U}$ homogeneously distributed in an empty $200 \mathrm{~L}$ drum (without waste matrix).

The intense peak up to $200 \mu$ s visible on Figure 5 is caused by the detection of fast neutrons emitted during the generator pulse. After the pulse, designs \#2 to \#5 including a polyethylene moderator around the generator show a higher $\varepsilon \times \mathrm{R}_{\text {fis }}(\mathrm{t})$ signal than with graphite only, due to a more efficient neutron thermalization with such limited moderator dimensions, resulting in a higher fission rate (see also Table I below). A [600 $\mu \mathrm{s}-3000 \mu \mathrm{s}]$ time gate is used to record induced-fission prompt neutrons. To compare the performances of the six designs, we define two Figures of Merit (FOM) for the passive and active measurements, respectively:

$$
\begin{aligned}
& \text { FOM }_{\text {passive }}=\frac{\varepsilon^{2}}{T_{1 / 2 b}} \\
& \text { FOM }_{\text {active }}=\varepsilon \cdot R_{\text {fis }}
\end{aligned}
$$

The performances calculated for the six designs are reported in Table I. The calculated relative uncertainty of $\varepsilon$ and $R_{\text {fis }}$ never exceeds $1 \%$.

Table I. Performance metrics of the six preliminary designs of the MICADO neutron system.

\begin{tabular}{|c|c|c|c|c|c|c|}
\hline Design & $\# 1$ & $\# 2$ & $\# 3$ & $\# 4$ & $\# 5$ & $\# 6$ \\
\hline$\varepsilon(\%)$ & 11.9 & 10.0 & 10.3 & 9.85 & 11.0 & 12.1 \\
\hline $\mathrm{T}_{1 / 2 \mathrm{~b}}(\mu \mathrm{s})$ & 19.4 & 20.0 & 18.7 & 18.5 & 18.9 & 19.3 \\
\hline $\begin{array}{c}\boldsymbol{F O M} \boldsymbol{M}_{\text {passive }} \\
\left(\boldsymbol{\mu s}^{-1}\right)\end{array}$ & $\mathbf{7 . 3 2}$ & $\mathbf{5 . 0 2}$ & $\mathbf{5 . 7 5}$ & $\mathbf{5 . 2 4}$ & $\mathbf{6 . 3 7}$ & $\mathbf{7 . 6 2}$ \\
\hline $\boldsymbol{F O M}_{\text {passive }}^{\text {norm }}$ & $\mathbf{0 . 9 6}$ & $\mathbf{0 . 6 6}$ & $\mathbf{0 . 7 5}$ & $\mathbf{0 . 6 9}$ & $\mathbf{0 . 8 4}$ & $\mathbf{1}$ \\
\hline $\begin{array}{c}\mathrm{R}_{\text {fis }} \\
\left(10^{2} \mathrm{~s}^{-1} \cdot \mathrm{g}^{-1}\right)\end{array}$ & 5.76 & 14.1 & 15.5 & 16.7 & 17.8 & 7.28 \\
\hline $\begin{array}{c}\boldsymbol{F O M}^{\boldsymbol{M}_{\text {active }}} \\
\left(10^{3} \mathrm{~s}^{-1} \cdot \mathrm{g}^{-1}\right)\end{array}$ & $\mathbf{6 . 8 7}$ & $\mathbf{1 4 . 1}$ & $\mathbf{1 6 . 1}$ & $\mathbf{1 6 . 4}$ & $\mathbf{1 9 . 5}$ & $\mathbf{8 . 8 3}$ \\
\hline $\boldsymbol{F O M}_{\text {active }}^{\text {norm }}$ & $\mathbf{0 . 3 5}$ & $\mathbf{0 . 7 2}$ & $\mathbf{0 . 8 3}$ & $\mathbf{0 . 8 4}$ & $\mathbf{1}$ & $\mathbf{0 . 4 5}$ \\
\hline
\end{tabular}

The FOM was also normalized to the best performing design in both passive and active mode to better compare the designs. The discrepancy between the six designs is quite limited in passive mode, both in terms of detection efficiency $(\varepsilon)$ and $\mathrm{FOM}_{\text {passive, }}$ but the fission rate in active mode is much more sensitive to the design. The highest FOMactive is obtained with design \#5, well above the other designs. It is interesting to note that the two graphite pillars around the generator improve both detection efficiency and fission rate, with respect to design \#2 (without the two pillars) or design \#4 (polyethylene pillars). Indeed, neutron scattering in graphite guides the interrogating generator neutrons toward the drum and enhance the fission rate. Additionally, graphite reflects part of fission prompt neutrons toward detectors, with less moderation than polyethylene, hence limiting their absorption by the cadmium layer enveloping detection blocks. Although design \#5 is not the best for passive neutron coincidence counting, with a normalized FOM of 0.84 with respect to design \#6, it appears as a good trade-off between the passive and active measurements. In facilities where only passive measurements could be performed, however, a system inspired from design \#6, but without the generator and the two pillars, would be sufficient.

\section{DESIGN OF THE MICADO PROTOTYPE}

Security rules of nuclear facilities and practical constraints for in-situ measurements, especially on the weight of the system because of ground load limitations and seismic risk mitigation, led us to focus on the polyethylene moderator. In addition, graphite is more inflammable and more difficult to clean up in case of contamination. Therefore, the graphite walls of the cell have been replaced by polyethylene with a reduced thickness of $10 \mathrm{~cm}$. In addition, the graphite pedestal under the drum and the two pillars near the generator have been removed from the final design, see Figure 6. In this way, the moderator mass can be reduced from about 4 to 1 ton. On the other hand, as neutron detection efficiency significantly drops with polyethylene instead of graphite walls $(4.90 \%$, i.e. about a factor 2 lower than the values in Table I), four detection blocks have been added in the cavity, which finally leads to a detection efficiency of $6.75 \%$. On the other hand, the fission rate is $1.24 \times 10^{3} \mathrm{~s}^{-1} \cdot \mathrm{g}^{-1}$ (in a slightly modified window: [620 $\mu$ s $-2660 \mu$ s]), which is comparable to the values of Table I. One can also note the addition of a boron coated detector behind the neutron generator to monitor its emission ("external monitor"), while the two "internal monitors" are still present inside the measurement cell, at the opposite side of the drum with respect to the generator. The external monitor should indeed be insensitive to the drum, while the internal monitors will be used to correct for waste matrix effects.

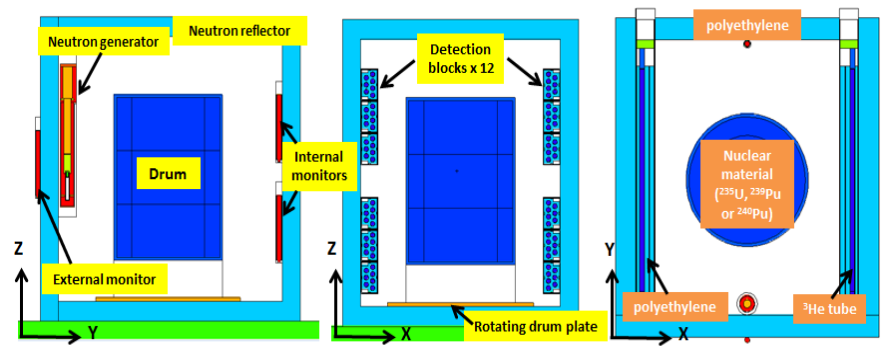

Fig. 6. MCNP model of the MICADO neutron system design. 


\section{SENSITIVITY AND DETECTION LIMITS}

The quantity of interest is the nuclear material mass in the waste drum, which is generally given as an equivalent mass $\left(\mathrm{m}_{\mathrm{eq}}\right)$ of ${ }^{240} \mathrm{Pu},{ }^{235} \mathrm{U}$ or ${ }^{239} \mathrm{Pu}$, independently of the isotopic composition. This equivalent mass is proportional to the useful signal $\left(\mathrm{S}_{\mathrm{u}}\right.$ in $\mathrm{s}^{-1}$ ) and a calibration coefficient ( $\mathrm{CC}$ in $\mathrm{s}^{-1} \cdot \mathrm{g}^{-1}$ ) allows determining $\mathrm{m}_{\mathrm{eq}}$ :

$$
m_{e q}=\frac{s_{u}}{C C}
$$

In passive mode, $S_{\mathrm{u}}$ corresponds to real coincidences (neutron pairs) after subtraction of accidental coincidences, while in active mode, $S_{\mathrm{u}}$ is the net signal due to fission prompt neutrons, after subtraction of the active background.

In passive mode, the $\mathrm{CC}$ for ${ }^{240} \mathrm{Pu}$ is expressed as follow:

$$
\mathrm{CC}_{\text {passive }}=\tau_{\text {fis }, 240_{P u}} \cdot\left(\frac{\overline{v(v-1)}}{2}\right)_{240_{P u}} \cdot \varepsilon^{2} \cdot \mathrm{e}^{-\frac{\ln 2}{\mathrm{~T}_{1 / 2 \mathrm{~b}}} \cdot \mathrm{t}_{\mathrm{d}}} \cdot\left(1-\mathrm{e}^{-\frac{\ln 2}{\mathrm{~T}_{1 / 2 \mathrm{~b}}} \cdot \theta}\right)
$$

With $\tau_{\mathrm{fis}, 240_{P u}}=478$ fission. $\mathrm{s}^{-1} \cdot \mathrm{g}^{-1}$ the spontaneous fission rate per gram of ${ }^{240} \mathrm{Pu} ;\left(\frac{\overline{v(v-1)}}{2}\right)_{240_{P u}}=1.89$ the average number of neutron pairs that can be formed per spontaneous fission of ${ }^{240} \mathrm{Pu}$; to a pre-delay to take into account the electronics dead time after the detection of the first coincident neutron (typical value of $4 \mu \mathrm{s})$; and $\theta$ the length of the coincident gate defined empirically and related to $\mathrm{T}_{1 / 2 \mathrm{~b}}$ [PAN91] (around $31 \mu \mathrm{s}$ for this neutron system design). The $\mathrm{CC}$ calculated in passive neutron coincidence counting is $2.39 \mathrm{~s}^{-1} \cdot \mathrm{g}^{-1}$ when ${ }^{240} \mathrm{Pu}$ is homogenously distributed in an empty $200 \mathrm{~L}$ drum without matrix.

In active mode, the CC is expressed as follow:

$$
C C_{\text {active }}=\bar{v} \cdot \varepsilon \cdot \frac{R_{f i s}}{t_{g_{2}}-\operatorname{tg}_{1}} \cdot \frac{\bar{E}_{\text {gen }}}{f_{\text {gen }}} \cdot k_{\text {det }} \cdot k_{\text {conv }}
$$

With $\bar{v}$ the average number of prompt neutrons emitted per fission of ${ }^{235} \mathrm{U}$ or ${ }^{239} \mathrm{Pu}$; $\mathrm{f}_{\text {gen }}$ the frequency of the neutron generator $(125 \mathrm{~Hz}) ; \operatorname{tg}_{1}$ and $\operatorname{tg}_{2}$ the boundaries of the time gate in which fission prompt neutrons are counted (to optimize the operation of the new GENIE 16 procured by the Nuclear Measurement Laboratory, the pulse length is now $800 \mu \mathrm{s}$ instead of $200 \mu$ s previously, and accordingly $\operatorname{tg}_{1}$ and $\operatorname{tg}_{2}$ are $1220 \mu$ s and $3260 \mu$ s, respectively); $\bar{E}_{g e n}$ the average emission of the neutron generator $\left(3.2 \times 10^{8} \mathrm{~s}^{-1}\right)$; and $\mathrm{k}_{\text {conv }}$ is a convolution factor to correct for the time difference between a fission and the detection of its prompt neutrons (indeed, Eq. 4 involves a two-step calculation, first the fission rate $R_{f i s}$ and then the prompt neutron detection efficiency $\varepsilon$, which does not account for this difference): $\mathrm{k}_{\text {conv }}$ is here close to unity because $\mathrm{T}_{1 / 2 \mathrm{~b}}$ is small compared to $\mathrm{T}_{1 / 2 \mathrm{c}}$. The calculated $\mathrm{CC}$ in active neutron interrogation is $185 \mathrm{~s}^{-1} \cdot \mathrm{g}^{-1}$ and $299 \mathrm{~s}^{-1} \cdot \mathrm{g}^{-1}$ for ${ }^{235} \mathrm{U}$ and ${ }^{239} \mathrm{Pu}$, respectively, homogeneously distributed in an empty drum without matrix.

The performances of the neutron system for drums filled with a waste matrix depend on its thermalizing and absorbing properties. Globally, neutron coincidence counting is not much sensitive to metallic matrices, but in rich-in-hydrogen waste materials, the useful signal can be significantly reduced due to the thermalization of spontaneous fission neutrons and to their subsequent absorption by the cadmium layer surrounding detection blocks. Fission prompt neutron counting in active mode is more impacted by the amount of thermalizing and absorbing materials present in the matrix, since the thermal interrogating neutron flux is even more dependent on these properties than detection efficiency. Therefore, we have simulated four different matrices homogeneously distributed inside the drum. Matrix \#1 is made of stainless steel with an apparent density of $0.7 \mathrm{~g} . \mathrm{cm}^{-3}$. Matrix \#2 and \#3 are hydrogenrich matrices made of polyethylene with an apparent density of 0.1 g.cm ${ }^{-3}$ and 0.7 g.cm ${ }^{-3}$, respectively. Matrix \#4 is a mixture of polyethylene (34\% mass fraction) and stainless steel (66\% mass fraction) with an apparent density of $0.5 \mathrm{~g} . \mathrm{cm}^{-3}$. Figure 7 shows the evolution of $\varepsilon \times \mathrm{R}_{\text {fis }}$ over time for these different matrices and for the empty drum.

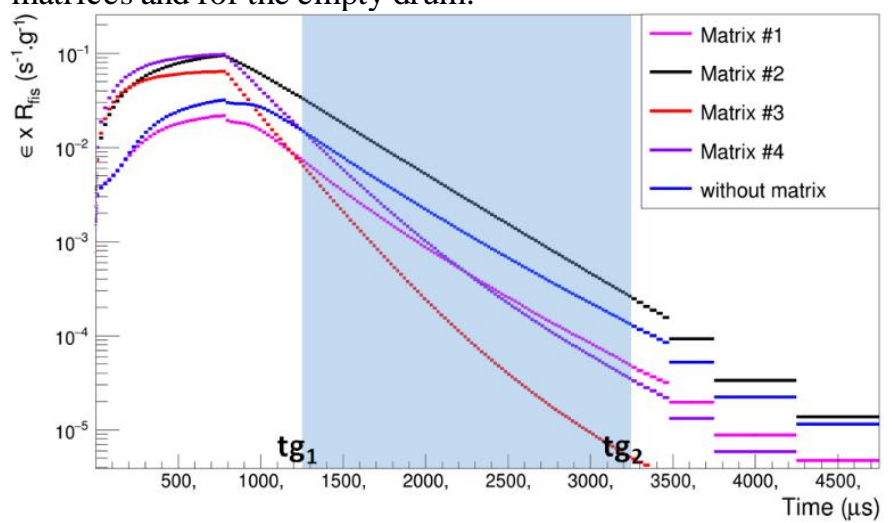

Fig. 7. Evolution of $\varepsilon \times \mathrm{R}_{\mathrm{fis}}(\mathrm{t})$ in active neutron interrogation of ${ }^{235} \mathrm{U}$ homogenously distributed in different matrices. The blue area represents the time gate for induced-fission prompt neutron counting (useful signal).

During the generator pulse, matrices containing polyethylene (i.e. Matrix \#2,\#3 and \#4) show the highest $\varepsilon \times R_{\text {fis }}$ product, while the absence of thermalizing material for Matrix \#1 and the empty drum give a lower $\varepsilon \times \mathrm{R}_{\text {fis }}$ product. After the generator pulse, the decay of $\varepsilon \times R_{\text {fis }}$ is driven by $T_{1 / 2}$, which depends on the matrix composition. The fast decay of $\varepsilon \times \mathrm{R}_{\mathrm{fis}}$ for Matrix \#3 and \#4 is caused by the high amount of thermalizing and absorbing materials. The slower decay for Matrix \#2 is due to its lower density. Although very dense and absorbing, the impact of Matrix \#1 on $\varepsilon \times \mathrm{R}_{\text {fis }}$ is very low and similar to that of the empty drum. Indeed, as Matrix \#1 is purely metallic, it does not participate to neutron moderation and thermal interrogating neutrons (moderated in the measurement system walls but not in the waste matrix) are mainly absorbed in the cadmium layers surrounding detection blocks and secondarily in the stainless steel matrix. Beyond these qualitative effects observed in Figure 7, the useful signal for the different matrices, represented by the calibration coefficients $\mathrm{CC}_{\text {passive }}$ (Eq. 3) and $\mathrm{CC}_{\text {active }}$ (Eq.4), are given in Table II.

Table II. Calibration coefficients calculated for different matrices in passive and active modes. 
THIS IS A PREPRINT OF AN ARTICLE PUBLISHEDIN NIMA. VERSION DATE: 01/2021 - LINK OF THE ORIGINAL PUBLICATION: DOI:

10.1016/J.NIMA.2021.165398 - REFERENCE OF THE ARTICLE: NUCLEAR INST. AND METHODS IN PHYSICS RESEARCH, A 1005 (2021) 165398 - POSTPRINT

MUST BE POSTED IN HAL-CEA INSTEAD OF THE PREPRINT AFTER THE EM BARGO PERIOD (24 M ONTHS FOR NIMA)

\begin{tabular}{|c|c|c|c|}
\hline Matrix & $\begin{array}{c}\mathbf{C C}_{\text {passive }} \\
\left(\mathrm{s}^{-1} \cdot \mathrm{g}^{-1} \mathrm{of}^{24} \mathrm{Pu}\right)\end{array}$ & $\begin{array}{c}\mathbf{C C}_{\text {active }} \\
\left(\mathrm{s}^{-1} \cdot \mathrm{g}^{-1} \text { of }^{235} \mathrm{U}\right)\end{array}$ & $\left.\begin{array}{c}\mathbf{C C}_{\text {active }} \\
\left(\mathrm{s}^{-1} \cdot \mathrm{g}^{-1} \text { of }\right.\end{array}{ }^{239} \mathrm{Pu}\right)$ \\
\hline$\# 1$ & 2.61 & 84 & 138 \\
\hline$\# 2$ & 2.37 & 430 & 687 \\
\hline$\# 3$ & 0.34 & 47 & 76 \\
\hline $\begin{array}{c}\text { Without } \\
\text { matrix }\end{array}$ & 1.50 & 141 & 228 \\
\hline
\end{tabular}

$$
\begin{gathered}
M D L_{\text {active }}=\frac{4}{C C_{\text {active }} \cdot\left[1-4\left(\sigma_{\text {relEM }}^{2}+\frac{1}{E M \cdot t_{M}}\right)\right]} \times \\
\sqrt{B G_{\text {active }}{ }^{2} \cdot k_{r p}{ }^{2}\left(\frac{\sigma_{k_{r p}}^{2}}{k_{r p}}+2 \sigma_{\text {relEM }}^{2}+2 \sigma_{\text {relG } 16}^{2}+\frac{1}{E M \cdot t_{M}}+\frac{1}{E M_{B G} \cdot t_{M B G}}\right)}
\end{gathered}
$$

with EM and EMBG the signals of the external monitor with and without drum during effective measurement times $\mathrm{t}_{\mathrm{M}}$ and $\mathrm{t}_{\mathrm{MBG}}$, respectively; $B G_{\text {active }}$ the active background without drum (in the time gate used to record fission prompt neutrons); $k_{r p}$ a coefficient to take into account the impact of the drum on the active background measured without drum, and $\sigma_{k r p}$ its standard deviation; $\sigma_{\text {relEm }}$ a relative standard deviation representing the uncertainty caused by the influence of the drum matrix on the external monitor signal (which should be negligible, but in practice we use an $1.3 \%$ uncertainty assessed on a similar system); $\sigma_{\text {relG16 }}$ another relative uncertainty on the active background caused by the residual neutron emission between the pulses of the generator ("cold emission"), estimated to $2 \%$ from our user feedback of GENIE 16 generator. The MDL of the neutron system for the different matrices in passive and active modes are reported in Table III for a 30 min measurement time.

Table III. Mass detection limits calculated for different waste matrices in passive and active modes.

\begin{tabular}{|c|c|c|c|}
\hline Matrix & $\begin{array}{c}\mathbf{M D L}_{\text {passive }} \\
\left(\mathrm{g} \mathrm{of}^{20} \mathrm{Pu}\right)\end{array}$ & $\begin{array}{c}\mathbf{M D L}_{\text {active }} \\
\left(\mathrm{g} \mathrm{of}^{235} \mathrm{U}\right)\end{array}$ & $\begin{array}{c}\mathbf{M D L}_{\text {active }} \\
\left(\mathrm{g} \mathrm{of}^{239} \mathrm{Pu}\right)\end{array}$ \\
\hline$\# 1$ & 0.068 & 0.315 & 0.192 \\
\hline$\# 2$ & 0.075 & 0.062 & 0.039 \\
\hline$\# 3$ & 0.519 & 0.564 & 0.349 \\
\hline $\begin{array}{c}\text { Without } \\
\text { matrix }\end{array}$ & 0.119 & 0.188 & 0.116 \\
\hline
\end{tabular}

The MDL results demonstrate the capabilities of the neutron system to detect less than $1 \mathrm{~g}$ of ${ }^{240} \mathrm{Pu},{ }^{235} \mathrm{U}$ or ${ }^{239} \mathrm{Pu}$ (equivalent mass) in passive or active modes, in a wide range of waste matrices. However, these a priori MDL estimations are valid only for the abovementioned assumptions, and experimental MDL have to be determined further in MICADO project. If the MICADO neutron system should allow the detection of nuclear materials in sub-gram quantities in both passive and active modes, it can be noted, however, that significant matrix effects are expected, the correction of which being the topic of next studies.

\section{CONCLUSION}

The MICADO neutron measurement system has been designed by MCNP simulation, with the objective to estimate the nuclear material mass in a wide range of radioactive waste drums by passive neutron coincidence counting and active neutron interrogation. The investigation of six preliminary designs has demonstrated the interest of combining the moderation and reflection properties of graphite and polyethylene to optimize both the detection efficiency and the induced fission rate. given by Eq. 8: 
However, the design of the MICADO neutron system prototype had to be adapted to practical constraints, mainly regarding the total weight of the measurement cell, leading to the choice of polyethylene walls only to reduce by a factor 4 the moderator mass with respect to graphite ( 1 ton vs. 4 tons), while preserving sufficient overall performances. Estimations of the detection limits in 30 min measurements indeed show that less than $1 \mathrm{~g}$ of ${ }^{240} \mathrm{Pu},{ }^{235} \mathrm{U}$ or ${ }^{239} \mathrm{Pu}$ can be detected in $200 \mathrm{~L}$ drums filled with different matrices, covering the expected range of drums that will be assessed with MICADO neutron cell. However, significant matrix effects are observed, both in passive mode (with rich-in-hydrogen moderating matrices) and in active mode (with neutron absorbing waste materials), which will be studied extensively by numerical simulation in next steps, to define appropriate corrections based on matrix monitors. Then, the simulated performances presented in this work will be validated by experiments planned in DANAIDES casemate of TOTEM nuclear facility, at CEA Cadarache, France, with the neutron system prototype currently under construction by MICADO Partners (CAEN, ENEA, CEA).

\section{REFERENCES}

[AN15] R. Antoni, C. Passard, B. Perot, M. Batifol, J-C. Vandamme, G. Grassi, First Industrial Tests of a Matrix Monitor Correction for the Differential Die away Technique of Historic Waste Drums, ANIMMA 2015, Advancements in Nuclear Instrumentation Measurement Methods and their Applications, 20-24 April 2015, Lisbon, Portugal.

[CAL86] J. T. Caldwell et al., "The Los Alamos Second-Generation System for Passive and Active Neutron Assays of Drum-Size Containers", vol. LA-10774MS. 1986

[CHE16] N. Cherubini et al., "Field Prototype of the ENEA Neutron Active Interrogation Device for the Detection of Dirty Bombs," Challenges 2016, pp. 7(2), 17.

[CHE18] N. Cherubini et al., "The Neutron Active Interrogation System for InField Detection of Transuranic-Based Radioactive Dispersal Devices for Security Applications, Proceedings of the 2018," in 26th International Conference on Nuclear Engineering, ICONE26,, London, England, July 22-26, 2018.

[CIF86] D.M. Cifarelli \& W. Hage Nucl. Instr. \& Meth. A251 (1986) 550-563 [GEN16] https://www.nrc.gov/docs/ML1408/ML14085A270.pdf

[MCNP6] MCNP user's manual Code version 6.2, October 27, 2017. [MIC] https://www.micado-project.eu/

[PAN91] N. Ensslin et al, "Principles of neutron coincidence counters", 1991. Passive nondestructive as say of nuclear materials (LA-UR-90-732).

[PE18] B. Perot et al. The characterization of radioactive waste: a critical review of techniques implemented or under development at CEA, France, EPJ Nuclear Sci. Technol. 4, 3 (2018).

[REM17] R. Remetti et al. , "In field application of differential Die-Away time technique for detecting gram quantities of fissile materials," Nuclear Instruments and Methods in Physics Research, Section A, Accelerators Spectrometers Detectors and Associated Equipment, vol. Volume 870, pp. Pages 123-130, 21 October 2017.

[SIM16] E. Simon et al. "Study of fissile mass quantification by photofission delayed gamma rays in radioactive waste packages using MCNPX", Nuclear Instruments and Methods in Physics Research A 840 (2016) 28-35 